\title{
Use of Direct Current Resistivity Measurements to Assess AISI 304 Austenitic Stainless Steel Sensitization
}

\author{
Ramaiany Carneiro Mesquita ${ }^{a}$,José Manoel Rivas Mecury
}

Auro Atsumi Tanaka ${ }^{b}$, Regina Célia de Sousa ${ }^{b *}$

\author{
aPrograma de Pós-Graduação em Engenharia de Materiais, Instituto Federal de Educação, Ciência \\ e Tecnologia do Maranhão - IFMA, Av. Getúlio Vargas, 4, CEP 65030-005, São Luís, MA, Brasil \\ ${ }^{b}$ Universidade Federal do Maranhão - UFMA, Av. dos Portugueses, 1966, Cidade Universitária, \\ CEP 65080-805, São Luís, MA, Brasil
}

Received: July 9, 2014; Revised: February 16, 2015

\begin{abstract}
This paper describes the feasibility of using direct current electrical resistivity measurements to evaluate AISI 304 austenitic stainless steel sensitization. ASTM A262 - Practice A and double loop electrochemical potentiodynamic reactivation (DL-EPR) tests were performed to assess the degree of sensitization (DoS) qualitatively and quantitatively, and electrical resistivity (ER) was measured by the four-point direct-current potential drop method. The results indicate that the DoS increases rapidly while the ER decreases gradually in response to increasing sensitization. Thereafter, the two parameters tend to remain approximately constant. This behavior may be due to the rapid increase in the volume fraction of $\mathrm{M}_{23} \mathrm{C}_{6}$ precipitates over a sensitization time of 4 to 6 hours, thereafter remaining relatively constant. The ER results, which were corroborated by other techniques used in this study, confirm the promising potential of this property to monitor the sensitization phenomenon in AISI 304 steel.
\end{abstract}

Keywords: AISI 304 steel, sensitization, electrical resistivity, DL-EPR tests

\section{Introduction}

Austenitic stainless steels (ASS) are well known for their high corrosion resistance in various aggressive environments and for their good mechanical properties at high temperatures. These characteristics have led to their widespread industrial use, particularly by the chemical and petrochemical industries, often under severe operating conditions. However, when in service, they are subject to intergranular corrosion resulting from grain boundary precipitation of chromium-rich carbides, particularly $\mathrm{M}_{23} \mathrm{C}_{6}$, at temperatures ranging from 400 to $900{ }^{\circ} \mathrm{C}^{1-3}$. This precipitation reduces the concentration of chromium in the regions adjacent to the grain boundaries to levels below that required for steel to passivate, making them susceptible to intergranular corrosion, i.e., sensitizing them. When exposed to corrosive environments, sensitized ASS undergo dissolution of their chromium-depleted regions, which may lead to intergranular corrosion ${ }^{4,5}$.

Sensitization in industrial components made of ASS impairs their structural integrity, rendering their operation unsafe. Periodic inspections are therefore necessary to evaluate the degradation of these components, particularly for the early detection of a problem long before it can worsen. To this end, it is important to determine the conditions under which sensitization occurs, using various and preferably non-destructive testing methods to obtain technical information for the optimization of maintenance and component replacement management, thereby preventing the occurrence of accidents.

*e-mail: sregina@ufma.br
The techniques most commonly employed to assess the DoS of stainless steel components, which can become sensitized after their manufacture or in service, are the DL-EPR test proposed by Akashi et al. ${ }^{6}$ and the oxalic acid etch test specified by ASTM A262 - Practice A ${ }^{7}$. Some alternatives for fast reliable non-destructive testing have been proposed to evaluate the effects of aging in stainless steel. Ortiz et al. ${ }^{8}$ measured thermoelectric voltage to determine the DoS of duplex stainless steel. Shaikh et al. ${ }^{9}$ applied the eddy current testing technique to assess and quantify the DoS and intergranular corrosion in thermally aged AISI 316 stainless steel. Wasnik et al. ${ }^{1}$ conducted a detailed study to identify different stages of precipitation in $316 \mathrm{~L}$ ASS, using electrical resistivity measurements associated with differential scanning calorimetry and transmission electron microscopy.

Electrical resistivity measurements can be used to assess ASS sensitization, since this property also varies as a function of microstructural factors such as solute atoms, size and volume fraction of precipitates and dislocations, thus making it potentially interesting for monitoring components during service and/or machine downtime. It has been shown that although ER variations in degraded $\mathrm{Cr}-\mathrm{Mo}-\mathrm{V}$ steels are less than a few micro-ohms per $\mathrm{cm}$, they are detectable $\mathrm{e}^{10,11}$.

A reduction in ER may indicate precipitation, since the ER of a solid solution decreases in response to the depletion of solute elements, except in coherent precipitation (Guinier-Preston zones or pre-precipitate solute clusters), which increases ER ${ }^{1,12,13}$. Park et al. ${ }^{14}$ used ER measurements to 
determine the dissolution temperature of $\mathrm{Nb}(\mathrm{C}, \mathrm{N})$ precipitates in a low carbon microalloyed steel. They concluded that the ER increases proportionally with the increase in dissolved $\mathrm{Nb}$ content, due to the dissolution of $\mathrm{Nb}(\mathrm{C}, \mathrm{N})$ during the solution treatment. Moreover, it has been shown that the ER increases during the pre-precipitation of $\mathrm{AL}-\mathrm{Zn}-\mathrm{Mg}$ alloys when the typical radius of pre-precipitates is smaller than the mean free path of electrons ${ }^{15}$.

In this work, the ER was measured by the four-point direct-current potential drop method ${ }^{16-19}$. This method consists in applying a constant current between two probes and measuring the voltage between two others. The probes can be arranged in different ways ${ }^{17,19,20}$. The most common way is to arrange them inline and equidistantly on a flat surface of the material, as was done here. A current is then injected into the material through the two outer probes, and the resulting electric potential is measured across the inner pair ${ }^{18,19}$. The potential, $v$, is a function of the ER, $\rho$, the distance between the probes, $s$, and the current flowing through the probes, $i$. Based on the relative magnitudes of the sample thickness $(w)$ and the spacing between probes, resistivity is calculated as follows:

$\rho($ electrical resistivity $)=C\left(\frac{V}{i}\right)$

where $\mathrm{C}$ is equal to $2 \pi s$, for $w » s$, and $\pi \mathrm{w} / \ln 2$, for $w$ «s

Equation 1 is derived from the limit assumptions for thick and thin samples. Outside these limit situations, errors in resistivity measurements due to dimensional constraints do in fact occur, so a geometric correction factor $K$ should be used ${ }^{19}$.

$\rho=\left(\frac{V}{i}\right) K$

This work involved an investigation of the sensitization of a commercial AISI 304 steel treated at various temperatures and for different times, based on electrical resistivity measurements. Chemical and electrochemical techniques were also applied to obtain experimental measurements independent of the sensitization process, in order to validate the resistivity measurements.

\section{Experimental}

\subsection{Material and preparation of samples}

The material investigated here was AISI 304 austenitic stainless steel, which is widely used in the petrochemical industry and commercially available in $5 \mathrm{~mm}$ thick plates. Its chemical composition, which was determined by optical emission spectroscopy, was 0.08 wt. $\%$ C-1.1 wt. $\%$ Mn-0.79 wt $\%$ Si-8.00 wt. $\%$ Ni- 18.00 wt. $\%$ Cr. Samples with dimensions of $30 \mathrm{~mm} \times 40 \mathrm{~mm}$ were cut from a plate. Non-heat-treated samples were identified as "as-received" (AR). Fifteen AR samples were subjected to sensitization treatment at temperatures of 600,800 and $900{ }^{\circ} \mathrm{C}$ for $1,2,4,6$ and 12 hours, and were identified as "sensitized" (SE). To eliminate any residual sensitization in the as-received material, an AR sample was solution heat-treated at $1200{ }^{\circ} \mathrm{C}$ for 1 hour and was labeled "solubilized" (SO). All the samples were immediately quenched in water after undergoing heat treatment.

\subsection{Microstructural characterization}

The DoS of all the samples was determined qualitatively by metallographic analysis, according to ASTMA 262 - Practice $\mathrm{A}^{7}$. The samples surfaces were sanded with 180, 240, 400 and 600 grit sandpaper and polished with $1.0 \mu$ alumina $\left(\mathrm{Al}_{2} \mathrm{O}_{3}\right)$. An area of $1 \mathrm{~cm}^{2}$ on each sample was etched electrolytically with a solution of $10 \%$ (in weight) oxalic acid at a current density of $1 \mathrm{~A} / \mathrm{cm}^{2}$ for $1.5 \mathrm{~min}$, then cleaned and examined by optical microscopy. According to this standard, the microstructures thus obtained can be classified into three types: "step" structure, when there are no ditches at the grain boundaries; "dual" structure, when there are some ditches at the grain boundaries but no grains completely surrounded by ditches; and "ditch" structure, with one or more grains completely surrounded by ditches.

\subsection{Double loop electrochemical potentiodynamic reactivation (DL-EPR) tests}

The susceptibility of AISI 304 steel to intergranular attack was evaluated quantitatively based on DL-EPR tests performed at room temperature $\left(\sim 28^{\circ} \mathrm{C}\right)$ in a conventional three-electrode electrochemical cell with $\mathrm{Pt}$ foil as the auxiliary electrode and a saturated calomel electrode (SCE) as the reference electrode. The electrolytic solution was $0.5 \mathrm{M} \mathrm{H}_{2} \mathrm{SO}_{4}+0.01 \mathrm{M} \mathrm{KSCN}$. The working electrode was made of AISI 304 samples with an exposed surface area of $1 \mathrm{~cm}^{2}$. After the quasi-steady state open circuit potential $\left(\mathrm{E}_{\mathrm{oc}}\right)$ was reached (about 30 minutes), the potential was swept in the anodic direction up to $0.3 \mathrm{~V}$ (vs. SCE) at $1 \mathrm{mVs}^{-1}$ and then scanned back to the $\mathrm{E}_{\mathrm{oc}}$. The DL-EPR test was repeated at least four times on each sample to ensure its reproducibility. Prior to each test, the working electrodes were sanded successively with a series of sandpapers of up to 600 grit, then polished, degreased with water and alcohol, and dried in hot air. The DoS (or intensity of sensitization) was evaluated based on the $I r / I a$ ratio, where $I a$ and $I r$ represent the anodic and reverse peak currents, respectively ${ }^{2-4,6,21,22}$.

\subsection{Resistivity measurements}

The electrical resistivity of all the samples was measured at a constant temperature of $28.0 \pm 0.5^{\circ} \mathrm{C}$, using the four-point direct-current potential drop method ${ }^{10,19}$. The experimental setup consisted of four equidistant and collinear probes (the two outer probes supply current and the two inner ones measure voltage), a constant current source and a voltage meter. The probes, which were spaced $2.0 \mathrm{~mm}$ apart, and were lodged at the center of the samples, parallel to the length, during the measurements. The current used in these tests was $1.0 \mathrm{~A}$, and during the measurements its polarity was alternated to minimize measurement errors caused by thermal electromotive force ${ }^{10}$. Resistivity was calculated based on the average voltage of ten measurements, using Equation 3, derived from Equation 2,

$\rho=\left(\frac{V}{I}\right) w F_{1} F_{2}$

where $\mathrm{K}$ was substituted for $w, F_{1}$ and $F_{2}$, the latter two being correction factors of the sample's width and thickness, respectively ${ }^{19,23}$. 


\section{Results and Discussion}

Tests to check the structure according toASTMA262-PracticeA were applied to classify the DoS qualitatively, and the results of these tests were then correlated with the values of the DL-EPR and ER parameters.

Figure 1 illustrates the microstructures of samples with different DoS. The AR and SO samples, which show a

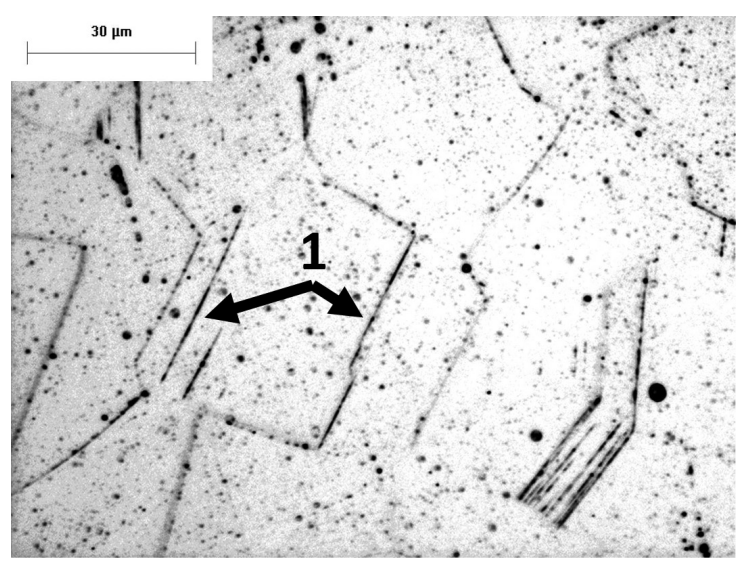

(a)

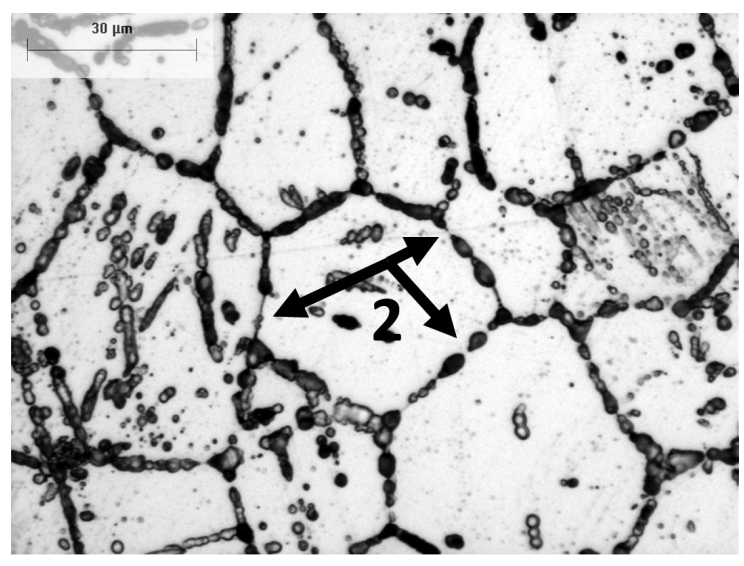

(b)

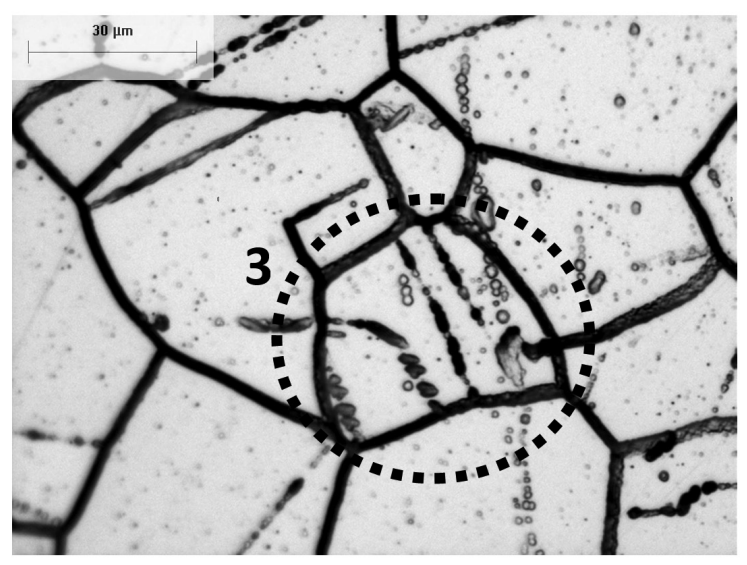

(c)

Figure 1. Optic micrographs of samples: (a) AR, (b) SE at 900 ${ }^{\circ} \mathrm{C}-2 \mathrm{~h}$, and (c) SE at $600{ }^{\circ} \mathrm{C}-2 \mathrm{~h}$. typically austenitic structure with extensive deformation twinning, indicated by the arrows (1), were classified as "step" structures [see Figure 1a]. The SE samples treated at $900{ }^{\circ} \mathrm{C}$ for 2 and 6 hours present a dual structure due to the discontinuous precipitation of $\mathrm{M}_{23} \mathrm{C}_{6}$ carbide at the grain boundaries [see Figure 1b]. The arrows (2) indicate the occurrence of intergranular corrosion in parts of the grain boundaries resulting from the electrolytic attack due to the existence Cr-depleted regions. All the other SE samples show a ditch structure due to the continuous precipitation of $\mathrm{M}_{23} \mathrm{C}_{6}$ at the grain boundaries [see Figure 1c]. The inset (3) shows a severely etched grain boundary. Table 1 summarizes the types of structures found in this study.

The $I r / I a$ ratio was used as a parameter to evaluate the DoS in the DL-EPR tests. Figure 2 shows curves of $\mathrm{AR}$ and $\mathrm{SE}$ samples obtained in these tests performed at 600 and $900{ }^{\circ} \mathrm{C}$ for 2 hours. The anodic polarization curves exhibit a similar behavior in each situation, with $I a$ values of 600 to $700 \mu \mathrm{A}$. However, after reversing the direction of the curve, i.e., the reactivation curve, the maximum current $\left(I_{R}\right)$ values differ considerably. The lower this value the lower the DoS, which is in agreement with results reported in the literature ${ }^{8,22,24}$. Table 1 summarizes the DoS found for each tested condition, while Figure 3 illustrates the behavior of DoS as a function of time at each temperature.

As can be seen in Table 1 and Figure 3, the DoS of the AR sample $(0 \mathrm{~h})$ showed the lowest value. Also note that the DoS showed a rapid increase over time up to about 2-4 h, thereafter tending to remain approximately constant. This decrease in the DoS growth rate after a sharp initial increase is reported in the literature, and is usually attributed to the desensitization caused by the diffusion of $\mathrm{Cr}$ from chromium-rich to chromium-depleted regions ${ }^{2,22,24}$. According to Majidi \& Streicher ${ }^{25}$, DoS values in the range of 0.0001 to 0.001 are associated with the step structure, while values ranging from 0.001 to 0.05 are attributed to the dual structure, and values higher than 0.05 to the ditch structure. The results in Table 1 indicate that the classifications of the structures and DoS fall within the aforementioned ranges, i.e., the DoS of the structure classified as step was

Table 1. Types of structure, DoS and ER of various samples.

\begin{tabular}{cccc}
\hline Sample & Microestruture & DoS (Ir/Ia) & ER (10-7 $\mathbf{\Omega . m})$ \\
\hline $\mathrm{AR}$ & Step & $0.0011 \pm 0.0012$ & $8.42 \pm 0.01$ \\
$600{ }^{\circ} \mathrm{C} / 1 \mathrm{~h}$ & Ditch & $0.549 \pm 0.022$ & $8.00 \pm 0.04$ \\
$600{ }^{\circ} \mathrm{C} / 2 \mathrm{~h}$ & Ditch & $0.500 \pm 0.033$ & $7.88 \pm 0.03$ \\
$600{ }^{\circ} \mathrm{C} / 4 \mathrm{~h}$ & Ditch & $0.561 \pm 0.013$ & $7.62 \pm 0.06$ \\
$600{ }^{\circ} \mathrm{C} / 6 \mathrm{~h}$ & Ditch & $0.570 \pm 0.016$ & $7.62 \pm 0.07$ \\
$600{ }^{\circ} \mathrm{C} / 12 \mathrm{~h}$ & Ditch & $0.563 \pm 0.022$ & $7.51 \pm 0.05$ \\
$800^{\circ} \mathrm{C} / 1 \mathrm{~h}$ & Ditch & $0.240 \pm 0.012$ & $8.20 \pm 0.06$ \\
$800^{\circ} \mathrm{C} / 2 \mathrm{~h}$ & Ditch & $0.300 \pm 0.014$ & $8.10 \pm 0.04$ \\
$800{ }^{\circ} \mathrm{C} / 4 \mathrm{~h}$ & Ditch & $0.247 \pm 0.014$ & $7.95 \pm 0.05$ \\
$800{ }^{\circ} \mathrm{C} / 6 \mathrm{~h}$ & Ditch & $0.220 \pm 0.021$ & $7.85 \pm 0.05$ \\
$800{ }^{\circ} \mathrm{C} / 12 \mathrm{~h}$ & Ditch & $0.199 \pm 0.012$ & $7.82 \pm 0.06$ \\
$900{ }^{\circ} \mathrm{C} / 1 \mathrm{~h}$ & Ditch & $0.063 \pm 0.011$ & $8.35 \pm 0.05$ \\
$900^{\circ} \mathrm{C} / 2 \mathrm{~h}$ & Dual & $0.040 \pm 0.011$ & $8.30 \pm 0.06$ \\
$900^{\circ} \mathrm{C} / 4 \mathrm{~h}$ & Ditch & $0.089 \pm 0.012$ & $8.21 \pm 0.07$ \\
$900{ }^{\circ} \mathrm{C} / 6 \mathrm{~h}$ & Dual & $0.051 \pm 0.031$ & $8.01 \pm 0.05$ \\
$900{ }^{\circ} \mathrm{C} / 12 \mathrm{~h}$ & Ditch & $0.055 \pm 0.023$ & $7.91 \pm 0.06$ \\
\hline
\end{tabular}




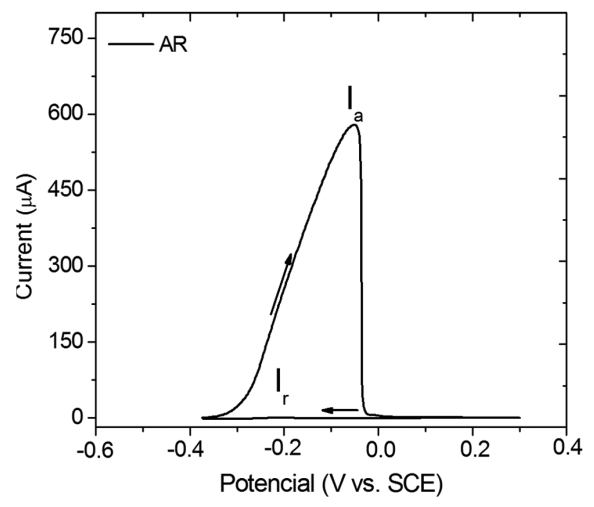

(a)

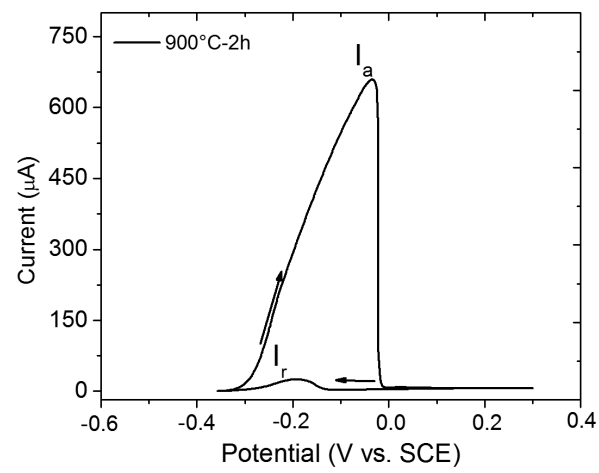

(b)

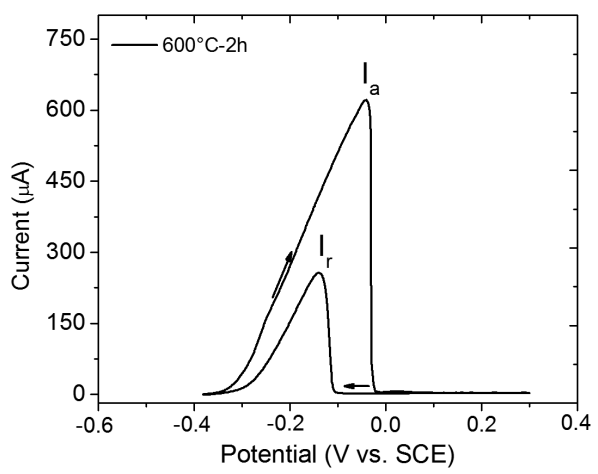

(c)

Figure 2. DL-EPR curves of samples: (a) AR, (b) SE at $900^{\circ} \mathrm{C}-2 \mathrm{~h}$, and (c) SE at $600{ }^{\circ} \mathrm{C}-2 \mathrm{~h}$.

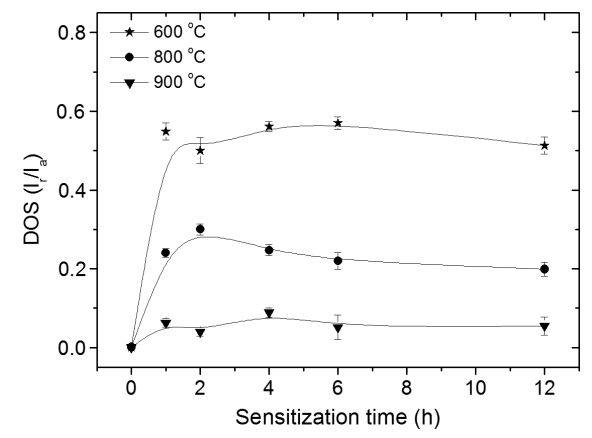

Figure 3. Behavior of DoS as a function of sensitization time at 600,800 and $900{ }^{\circ} \mathrm{C}$
0.001, that of the dual structure ranged from 0.040 to 0.051 , and that of the ditch structure varied from 0.055 to 0.570 . A comparison of these values with data reported in the literature obtained under similar heat treatment conditions and with DL-EPR tests indicated that the values of this study were relatively higher, possibly because the carbon content of the steel used here was about twice as high ${ }^{2,26,27}$.

In Figure 3, note that the DoS decreased in the range of $600-900{ }^{\circ} \mathrm{C}$ in response to increasing temperature. In stainless steel, the precipitation of $\mathrm{M}_{23} \mathrm{C}_{6}$ carbides is kinetically favored over other phases, and in fact is virtually inevitable, occurring between about 400 and $900{ }^{\circ} \mathrm{C}$. These precipitates may dissolve when exposed to longer aging times, giving rise to MC-type carbides and intermetallic phases such as sigma phase, which are more stable and contain less chromium, thus reducing sensitization ${ }^{28,29}$. The results depicted in Figure 3 indicate that $\mathrm{M}_{23} \mathrm{C}_{6}$ precipitation, or sensitization, within the temperature range of this study, reaches its highest intensity at $600{ }^{\circ} \mathrm{C}$, rendering the material highly susceptible to intergranular corrosion.

Table 1 lists the values of electrical resistivity, while Figure 4 illustrates its variation as a function of sensitization time at temperatures of 600,800 and $900{ }^{\circ} \mathrm{C}$. These results indicate that ER decreases over time and increases in response to increasing sensitization temperature.

The samples used in this study started with the same initial composition. However, after undergoing sensitization treatment, depending on the treatment time and temperature, the volumetric fraction of their precipitates showed variations. Since the ER measurements were taken at room temperature, we believe that only $\mathrm{Cr}_{23} \mathrm{C}_{6}$ precipitation in these samples, in different sensitization conditions, would have a significant effect on ER.

Electrical resistivity is sensitive to microstructural factors such as the concentration of voids and solute, and the size and volume fraction of precipitates. This sensitivity is due to the fact that these factors give rise to higher or lower scattering of conduction electrons, and is strongly dependent on the magnitude of these factors and on the mean free path of conduction electrons. ER increases when alloying elements dissolve in solid solution and decreases when they precipitate in the matrix ${ }^{1,12-14,30}$, except for coherent precipitation, which involves increased $\mathrm{ER}^{1,13,15}$.

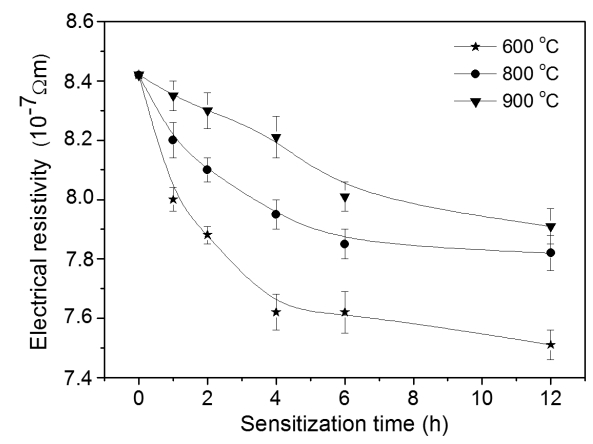

Figure 4. Behavior of ER as a function of sensitization time at 600,800 and $900{ }^{\circ} \mathrm{C}$. 
The results shown in Figure 4 and Table 1 justify the assumption that, at a given sensitization temperature, the volume fraction of precipitates increases rapidly (or the concentration of alloying elements in solution decreases) as a function of sensitization time of up to about 4-6 hours, thereafter remaining approximately constant. This statement is corroborated by the aforementioned DL-EPR results. The initial behavior of both DoS and ER (see Figures 3 and 4) can be attributed to the increase in the volume of chromium-rich carbide precipitates. On the other hand, the final behavior has generally been attributed to increasing $\mathrm{Cr}$ diffusivity, and in the case of relatively long times, to the appearance of more stable phases which contain less chromium, favoring the partial restoration of the concentration of chromium in solution, which is necessary for passivation to occur.

An analysis of the effect of the sensitization temperature on the ER results allows for the inference that the volume fraction of precipitates decreases in response to increasing temperature, a finding that is corroborated by the aforementioned DL-EPR test results. This is due to a decrease in the reaction kinetics of the formation of $\mathrm{Cr}_{23} \mathrm{C}_{6}$ carbides outside the interval of 600 to $700{ }^{\circ} \mathrm{C}^{4,28,29}$.

These results indicate the promising potential of using ER measurements to evaluate sensitization in austenitic stainless steels. However, a greater number of measurements taken under a variety of conditions are required to correlate ER and DoS mathematically, as well as other parameters.

\section{References}

1. Wasnik DN, Dey GK, Kain V and Samajdar I. Precipitation stages in a $316 \mathrm{~L}$ austenitic stainless steel. Scripta Materialia. 2003; 49(2):135-141. http://dx.doi.org/10.1016/S13596462(03)00220-3.

2. Tavares SSM, Fonseca MPC, Maia A and Lima-Neto P. Influence of the starting condition on the kinetics of sensitization and loss of toughness in an AISI 304 steel. Journal of Materials Science. 2003; 38(17):3527-3533. http://dx.doi.org/10.1023/A:1025652609061.

3. Lima AS, Nascimento AM, Abreu HFG and Lima-Neto P. Sensitization evaluation of the austenitic stailess steel AISI 304L, 316L, 321 and 347. Journal of Materials Science. 2005; 40(1):139-144. http://dx.doi.org/10.1007/s10853-005-5699-9.

4. Sedriks AJ. Corrosion of stainless steel. 2nd ed. New York: John Willey \& Sons; 1996.

5. Marshall P. Austenitic stainless steels, microstructure and mechanical properties. London: Elsevier Applied Science Publishers; 1984.

6. Akashi M, Kawarnoto T, Umemura F and Gijutsu B. Evaluation of IGSCC Susceptibility of Austenitic Stainless Steela Using Electrochemical Methods. Corrosion Engineering. 1980; 29:163-169.

7. American Society for Testing and Materials - ASTM. Annual Book of ASTM Standard: designation A-262-10-practice A. West Conshohocken; 2010.

8. Ortiz N, Curiel FF, López VH and Ruiz A. Evaluation of the intergranular corrosion susceptibility of UNS S31803 duplex stainless steel with thermoelectric power measurements. Corrosion Science. 2013; 69:236-244. http://dx.doi.org/10.1016/j. corsci.2012.12.008.

\section{Conclusions}

The results of this study led to the following conclusions:

- The DoS increased in response to decreasing sensitization temperature, while the ER decreased in the range of 600 to $900{ }^{\circ} \mathrm{C}$, probably due to the increase in the volume fraction of $\mathrm{M}_{23} \mathrm{C}_{6}$ precipitates.

- The DoS increased rapidly while the ER decreased over sensitization time, after which they tended to remain approximately constant. This behavior was probably due to the rapid increase in volume fraction of precipitates over a sensitization time of up to 4-6 hours, which thereafter remained approximately constant.

- The ER results, which were confirmed by other techniques used in this study, confirm the promising potential for studies of this property to monitor sensitization phenomena in AISI 304 steel.

\section{Acknowledgements}

The authors acknowledge the Brazilian research agency FINEP (Process No. 01.07.0313.00), CNPq (Process No. 455578/2012-5) and FAPEMA (Process APP-UNIVERSAL-00719/13) for its financial support of this work.

9. Shaikh H, Sivaibharasi N, Sasi B, Anita T, Amirthalingam R, Rao BPC, et al. Use of eddy current testing method in detection and evaluation of sensitization and intergranular corrosion in austenitic stainless steels. Corrosion Science. 2006; 48(6):14621482. http://dx.doi.org/10.1016/j.corsci.2005.05.017.

10. Nahm SH, Kim YI, Yu KM and Kim A. Evaluation of fracture toughness of degraded Cr-Mo-V steel using electrical resistivity. Journal of Materials Science. 2002; 37(16):3549-3553. http:// dx.doi.org/10.1023/A:1016587728470.

11. Seok C-S and Koo J-M. Evaluation of material degradation of $1 \mathrm{Cr}-1 \mathrm{Mo}-0.25 \mathrm{~V}$ steel by ball indentation and resistivity. Journal of Materials Science. 2006; 41(4):1081-1087. http:// dx.doi.org/10.1007/s10853-005-3644-6.

12. Bhargava NRMR, Samajdar I, Ranganathan S and Surappa MK. Role of SiCp reinforcements and trace elements on the $\mathrm{b} / \mathrm{b}$ precipitation in $\mathrm{Al}-10 \mathrm{Mg}$ alloy. Metallurgical and Materials Transactions A. 1998; 29A:2835-2842. http://dx.doi.org/10.1007/ s11661-998-0324-6.

13. Hatch JE. Aluminium properties and physical metallurgy. 7th ed. Ohio: ASTM; 1995.

14. Park JS and Lee YK. Determination of $\mathrm{Nb}(\mathrm{C}, \mathrm{N})$ dissolution temperature by electrical resistivity measurement in a low-carbon microalloyed steel. Scripta Materialia. 2007; 56(3):225-228. http://dx.doi.org/10.1016/j.scriptamat.2006.10.007.

15. Ferragut R, Somoza A and Torriani I. Pre-precipitation study in the $7012 \mathrm{Al}-\mathrm{Zn}-\mathrm{Mg}-\mathrm{Cu}$ alloy by electrical resistivity. Materials Science and Engineering A. 2002; 334(1-2):1-5. http://dx.doi. org/10.1016/S0921-5093(01)01771-3.

16. Valdes LB. Resistivity measurements on germanium for transistors. Proceedings of the IRE. 1954; 42(2):420-427. http:// dx.doi.org/10.1109/JRPROC.1954.274680. 
17. Swartzendruber LJ. Four-point probe measurement of nonuniformities in semiconductor sheet resistivity. Solid-State Electronics. 1964; 7(6):413-422. http://dx.doi.org/10.1016/00381101(64)90038-3.

18. Schuetze AP, Lewis W, Brown C and Geerts W. Laboratory on the four-point probe technique. American Journal of Physics. 2004; 72(2):149-153. http://dx.doi.org/10.1119/1.1629085.

19. Smits FM. Measurement of sheet resistivities with the four-point probe. The Bell System Technical Journal. 1958; 37(3):711-718. http://dx.doi.org/10.1002/j.1538-7305.1958.tb03883.x.

20. van der Pauw LJ. A method of measuring specific resistivity and Hall effect of discs of arbitrary shape. Philips Research Reports. 1958; 13:1-9.

21. Lima-Neto P, Farias JP, Herculano LFG, Miranda HC, Araújo WS, Jorcin J-B, et al. Determination of the sensitized zone extension in welded AISI 304 stainless steel using non-destructive electrochemical techniques. Corrosion Science. 2008; 50(4):11491155. http://dx.doi.org/10.1016/j.corsci.2007.07.014.

22. Hong J, Han D, Tan H, Li J and Jiang Y. Evaluation of aged duplex stainless steel UNS S32750 susceptibility to intergranular corrosion by optimized double loop electrochemical potentiokinetic reactivation method. Corrosion Science. 2013; 68:249-255. http://dx.doi.org/10.1016/j.corsci.2012.11.024.

23. Schroder DK. Semiconductor material and device characterization. New York: John Wiley \& Sons; 1990.

24. Beltran R, Maldonado JG, Murr LE and Fisher WW. Effects of strain and grain size on carbide precipitation and corrosion sensitization behavior in 304 stainless steel. Acta Materialia. 1997; 45(10):4351-4360. http://dx.doi.org/10.1016/S13596454(97)00106-7.

25. Majidi A and Streicher MA. The double loop reactivation method for detecting sensitization in AISI 304 stainless steels. Corrosion. 1984; 40(11):584-593. http://dx.doi.org/10.5006/1.3581921.

26. Taiwade RV, Patil AP, Patre SJ and Dayal RK. A comparative study of intergranular corrosion of AISI 304 stainless steel and chrome-manganese austenitic stainless steel. ISIJ International. 2012; 52(10):1879-1887. http://dx.doi.org/10.2355/ isijinternational.52.1879.

27. Yu X, Chen S, Liu Y and Ren F. A study of intergranular corrosion of austenitic stainless steel by electrochemical potentiodynamic reactivation, electro back-scattering difraction and cellular automaton. Corrosion Science. 2010; 52(6):1939-1947. http:// dx.doi.org/10.1016/j.corsci.2010.02.015.

28. Honeycombe RWK. Steels: microstructure and properties. London: Edward Arnold; 1981.

29. Lo KH, Shek CH and Lai JKL. Recent developments in stainless steels. Materials Science and Engineering R Reports. 2009; 65(4-6):39-104. http://dx.doi.org/10.1016/j.mser.2009.03.001.

30. Bhagat AN, Pabi SK, Ranganathan S and Mohanty ON. Study on copper precipitation during continuous heating and cooling of HSLA steels using electrical resistivity. Materials Science and Technology. 2007; 23(2):158-164. http://dx.doi. org/10.1179/174328407X157218. 